\title{
Comparison of Retrograde Femoral Interlocking Nail Versus Dynamic Condylar Screw in Distal Femoral Shaft Fractures
}

\author{
MUHAMMAD KAMRAN SHAFI', FRAZ NOOR ${ }^{2}$, SYED ALAM ZEB ${ }^{3}$, MUHAMMAD ISHFAQ $^{4}$, YOUSAF BIN TAHIR ${ }^{5}$, \\ TAUQEER NAWAZ KHAN 6 \\ ${ }^{1}$ Assistant Professor Orthopaedics BVH/QAMC, Bahawalpur \\ ${ }^{2}$ Assistant Professor Orthopaedics Sahara Medical College, Narowal \\ ${ }^{3}$ Specialist / Senior Registrar Orthopaedic Surgery, Dr. Sulaiman al Habib Medical Group, Riyadh KSA \\ ${ }^{4}$ Senior Registrar Orthopaedics, Nishtar Medical University and Hospital, Multan \\ ${ }^{5}$ Medical Officer Orthopaedic department Nishtar Hospital, Multan \\ ${ }^{6}$ Orthopedic Consultant DHQ hospital, Muzaffargarh \\ Corresponding author: Dr. Muhammad Kamran Shafi, E-mail: kamranshafi35@gmail.com, Contact: +923216864243
}

\begin{abstract}
Objective: The aim of this study is to compare the effectiveness of retrograde femoral interlocking nail versus dynamic condylar screw in distal femoral shaft fractures.

Study Design: Prospective/Randomized comprehensive

Place and Duration: Department of Orthopaedic Surgery Bahawal Victoria Hospital (BVH) / QAMC, Bahawalpur for duration of eight months i.e July 2020 to February 2021.

Methods: Total 65 patients of both genders were presented in this study with age ranges between 20-40 years. Patients detailed demographics age, sex and BMI were calculated after taking informed written consent. Patients were divided into 2- groups, I and II Group I had 32 patients and underwent for retrograde femoral interlocking nail and group II had 33 patients and received dynamic condylar screw. Mean operative time, mean union time of bones and complications were calculated. Effectiveness among both groups was calculated by HSS score. Complete data was analyzed by SPSS 22.0 version.

Results: Most of the patients were males 40 (61.54\%) and $25(38.46 \%)$ were females. Mean age of the patients in group I was $26.46 \pm 4.28$ years and in group II mean age was $30.78 \pm 8.22$ years. Mean operative time in group I was $82.8 \pm 7.14$ minutes while in group II it was $90.6 \pm 8.19$ minutes. Mean union time in group I was $22.7 \pm 2.5$ weeks and in group II was $26.21 \pm 5.3$ weeks. According to HSS score in group I $16(50 \%)$ results were excellent, $11(34.38 \%)$ was good, $3(9.8 \%)$ showed moderate and $2(6.25 \%)$ was poor, while in group II excellent results were $15(45.45 \%), 10(30.30 \%)$ was good, 5 (15.15\%) showed moderate and $3(9.09 \%)$ showed poor results. Complications were observed joint stiffness, delayed union, non union and varus deformity were significantly lower in group I as compared to group II.

Conclusion: We concluded in this comparison of study that bothretrograde femoral interlocking nail and dynamic condylar screw was useful and effective methods for trauma in distal femoral shaft fractures. But less union time and good outcomes were observed in interlocking nail as compared to dynamic condylar screw.
\end{abstract}

Keywords: Distal femoral shaft fractures, Trauma, Dynamic condylar, Interlocking nail

\section{INTRODUCTION}

There is controversy about the optimum approach to treat distal femoral fractures. These fractures are also complicated and managed with a variety of possible complications[1]. Varus and Valgus malalignment and malrotation are usually unsatisfactory, with high levels of ankylosis[1]. Implants, instrumentation and advanced surgical experience have been the traditional management of these fractures through surgical procedure. 1 The advent of locked plates enabled the biological percutaneous fixation of distal femoral fractures to be effectively used over a period [1-2].

Intramedullary fixation is a common technique for the stabilization of distal femour fractures since it is a biological method and also load-sharing that makes weightbearing easier.[3]

Intramedullary nailing may either be used to strengthen certain fractures in an antegrade or retrograde fashion. AIMN may lead to complications such as the Trendelenburg gait or the associated implant pain. Intramedullary (RIMN) retrograde nailing can cause complications, including damage to the cartilage around the intercondylar notch and knee dysfunction.
The standard management of Femur's displaced supracondyl fracture follows Watson Jones and John Charnley's principles, which consist of skeletal traction, fracture manipulation and external cast- and cast bracings immobilization. Complications such as deformity, cutting, long bed resting, stiffness of the knee, angulation, incongruity of joints, malunion, quadriceps, knee weakness and post-traumatic osteoarthritis were present in these approaches. Present developments include the application of $\mathrm{AO}$ blade plates, condylar screws and other implant systems such as supracondylar intramedullary nails. The shaft of Femur is frequently pushed laterally to the anatomical axis of the condyle by the application of an $A O$ blade plate or a dynamic condylar screw. This generates rotary motions on the split spot, causing blade plate or condylar screws to be pulled off and the plate is fatigued. In addition, osteoporotic bone contributes to implants failures by cutting the soft bone off with screws and plates. A minimally invasive procedure, whether using a nail or a plate, is essential to avoid these problems[4]. Stabilization of femoral distal fractures by retrograde nailing is a speedy procedure which does not require a comprehensive approach, and can therefore be performed with minimal 
blood loss by small incision[5]. In well selected patients, retrograde fémoral nailing using the updated technology was found healthy and successful[ 6,7$]$.

Retrograde intramedullary nailing showed clinical outcomes comparable to dynamic condylar screws (DCS) and newer fixed-angled systems, such as the Less Invasive Stabilizing System (LISS).[8-10]

The aim of this survey is to carry out a randomized, systematic treatment review in distal femoral fractures between the retrograde femoral nail and the dynamic condylar screw.

\section{MATERIAL AND METHODS}

This Prospective/Randomized comprehensive study was conducted at Department ofOrthopaedic Surgery Bahawal Victoria Hospital (BVH) / QAMC, Bahawalpur for duration of eight monthsi.e July 2020 to February 2021 and consists of 65 patients. Patients' detailed demographics age, sex and body mass index were calculated after taking informed consent. Patients with pathological fractures, unfit for anaesthesia and those did not give written consent were excluded from this study.

20-40 years of patients were presented in this study. Patients were divided into two groups, I and II. Group I had 32 patients and underwent for retrograde femoral interlocking nail and group II had 33 patients and received dynamic condylar screw. Types of fractures were classified by OTA technique, A1,A2 and A3. Mean operative time, mean union time of bones and complications were calculated. Effectiveness among both groups was calculated by HSS score. Categorical variables were assessed by frequency and percentage but descriptive variables were calculated by standard deviation. Complete data was analyzed by SPSS 22.0 version.

\section{RESULTS}

Most of the patients were males 40 (61.54\%) and 25 $(38.46 \%)$ were females. Mean age of the patients in group I was $26.46 \pm 4.28$ years and in group II mean age was $30.78 \pm 8.22$. Mean operative time in group I was $90.8 \pm 7.14$ minutes while in group II it was $78.6 \pm 8.19$ minutes. 45 $(69.23 \%)$ fractures were caused due road accidents, falling from height were $17(26.15 \%)$ and 3 (4.62\%) were others.(Table 1)

Table-1. Baseline detailed demographics on enrolled cases

\begin{tabular}{|c|c|c|}
\hline Variables & Group I $(n=32)$ & Group II $(n=33)$ \\
\hline \multicolumn{3}{|l|}{ Gender } \\
\hline Male & $20(30.8 \%)$ & $20(30.8 \%)$ \\
\hline Female & $12(18.5 \%)$ & $13(20 \%)$ \\
\hline Mean age (years) & $26.46 \pm 4.28$ & $30.78 \pm 8.22$ \\
\hline Mean operative time (mins) & $82.8 \pm 7.14$ & $90.6 \pm 8.19$ \\
\hline \multicolumn{3}{|l|}{ Types of fractures } \\
\hline A1 & $20(30.8 \%)$ & $20(30.8 \%)$ \\
\hline A2 & $9(13.85 \%)$ & $8(12.31 \%)$ \\
\hline A3 & $3(4.62 \%)$ & $5(7.7 \%)$ \\
\hline \multicolumn{3}{|l|}{ Causes of fractures } \\
\hline Road Accidents & $23(35.4 \%)$ & $22(33.84 \%)$ \\
\hline Fall from height & $8(12.31 \%)$ & $9(13.85 \%)$ \\
\hline Others & $1(1.54)$ & $2(3.1 \%)$ \\
\hline
\end{tabular}

Mean union time in group I was $22.7 \pm 2.5$ weeks and in group II was $26.21 \pm 5.3$ weeks. According to HSS score in group I 16 (50\%) results were excellent, 11 (34.38\%) was good, $3(9.8 \%)$ showed moderate and $2(6.25 \%)$ was poor, while in group II excellent results were 15 (45.45\%), $10(30.30 \%)$ was good, $5(15.15 \%)$ showed moderate and $3(9.09 \%)$ showed poor results. (Table 2$)$

Table 2: Association of outcomes among both groups

\begin{tabular}{|l|l|l|}
\hline Variables & Group I $(\mathrm{n}=32)$ & Group II $(\mathrm{n}=33)$ \\
\hline Mean union time (weeks) & $22.7 \pm 2.5$ & $26.21 \pm 5.3$ \\
\hline Outcomes (HSS score) & $16(50 \%)$ & $15(45.45 \%)$ \\
\hline Excellent & $11(34.38 \%)$ & $10(30.30 \%)$ \\
\hline Good & $3(9.8 \%)$ & $5(15.15 \%)$ \\
\hline Moderate & $2(6.25 \%)$ & $3(9.09 \%)$ \\
\hline Poor
\end{tabular}

Complications were observed joint stiffness, delayed union, non union and varus deformity were significantly lower in group I as compared to group II. (Table 3)

Table 3: Comparison of complications among both groups

\begin{tabular}{|l|c|c|}
\hline Complications & Group I $(\mathrm{n}=32)$ & Group I $(\mathrm{n}=33)$ \\
\hline Joint stiffness & $3(3.98 \%)$ & $5(15.15 \%)$ \\
\hline Delayed union & $2(6.25 \%)$ & $3(9.09 \%)$ \\
\hline Non-union & $1(3.13 \%)$ & $2(6.06 \%)$ \\
\hline Varus deformity & $1(3.13 \%)$ & $1(3.03 \%)$ \\
\hline
\end{tabular}

Rate of satisfaction among patients who received retrograde femoral interlocking nail were higher (78.13\%) as compared to the patients of dynamic condylar screw (66.67\%). (Table 4)

Table 4: Rate of satisfaction between both groups

\begin{tabular}{|l|l|c|}
\hline Variables & Group I $(\mathrm{n}=32)$ & Group I $(\mathrm{n}=33)$ \\
\hline Satisfaction & $25(78.13 \%)$ & $22(66.67 \%)$ \\
\hline Yes & $7(21.87 \%)$ & $11(33.33 \%)$ \\
\hline No &
\end{tabular}

\section{DISCUSSION}

Non-surgical treatment of distal femoral shaft fractures has been forgotten because of non-union, and mal-union [11]. Different forms of implants were used to repair these fractures over time[12, 13]. Intra-medullary nails[14], antegrade nailing with modified as well as external fixing allow fracture to be reduced and stabilized at minimum exposures, with the soft tissue dissection at the fractures location [15-16].In present study 65 patients of both genders were presented with age ranges 20-40 years. Majority of the patients $61.54 \%$ were males. Patients were classified into 2-groups, I and II. Group I had 32 patients and underwent for retrograde femoral interlocking nail and group II had 32 cases with dynamic condylar screw. There was no age $(26.46 \pm 4.28,30.78 \pm 8.22)$ difference among both groups. Our finding were similar to the previous some studies $[17,18]$.

In present study Mean operative time in group I was $82.8 \pm 7.14$ minutes while in group II it was $90.6 \pm 8.19$ minutes [19]. Mean union time in group I was 22.7 \pm 2.5 weeks and in group II was $26.21 \pm 5.3$ weeks. [20]A retrograde nailing with limited communation in extraarticular fractures will achieve a perfect and stable fixation. Since the soft tissue is preserved and the distal fracture fragment is best hold at a fracture site. The union rate is strong and the long-term complications are rare. Fixing 
fractures with multiple fractures can be also made easier in Polytrauma patients [21].

Both techniques were effective in our study but retrograde nailing was more effective. According to HSS score in group I, $16(50 \%)$ results were excellent, 11 (34.38\%) was good, 3 (9.8\%) showed moderate and 2 $(6.25 \%)$ was poor, while in group II excellent results were 15 (45.45\%), 10 (30.30\%) was good, 5 (15.15\%) showed moderate and $3(9.09 \%)$ showed poor results. These results showed resemblance to the previous many studies.[21-23] Most studies have concluded that placing Dynamic screw and RIMN in extra-articular distal femoral fractures are similar. Clinical outcome depends primarily on surgery rather than implant choice[25]. In both cases, patient satisfaction during the procedure is improved because less surgical dissection leads to less damage of soft tissue. You can easily use both methods. [26] However, there are also drawbacks of all of these approaches. The most significant drawback of the intramedullary nail procedure is that the implant must be placed by exposure of joint and, thus, septic arthritis may be caused. In the corresponding literature, septic arthritis was stated to be 0-14 per cent following retrograde nails. In our sample there have not been any retrograde nail infections or septic arthritis. [27, 28]

The majority of road traffic accidents were attributable to $69.23 \%$ and fall from heightis $26.15 \%$ and $4.62 \%$ due to other incidents. These observations were identical to the other. [22,23] Joint stiffness, delayed union, no union and deformity of the varus were observed in Group I significantly lower than in Group II. Compared to patients with dynamic condylar screws (66.67\%), satisfaction was higher among the patients who received retrograde femoral nails $(78,13 \%)$. While two methods tend to be equivalent to an excellent outcome for bone union in terms of lower blood loss and shorter operating period, Retrograde intramedullary nailing is better than DCS. [29] The following inference is therefore the same as the distal femoral nail of Handolin et al. is a reliable alternative in the treatment of distal femoral fractures with low complication rates. [30]

\section{CONCLUSION}

We concluded that bothretrograde femoral interlocking nail and dynamic condylar screw was useful and effective methods for trauma in distal femoral shaft fractures. But less union time and good outcomes were observed in interlocking nail as compared to dynamic condylar.

\section{REFERENCE}

1. Dar GN, Tak SR, Kangoo KA, Halwai MA. Bridge plate osteosynthesis using dynamic condylar screw (DCS) or retrograde intramedullary supracondylar nail (RIMSN) in the treatment of distal femoral fractures: comparison of two methods in a prospective randomized study. Ulus TravmaAcilCerrahiDerg. 2009;15:148-53

2. Seifert J, Stengel D, Matthes G, Hinz P, Ekkernkamp A., Ostermann, PA. Retrograde fixation of distal femoral fractures: results using a new nail system. J Orthop Trauma, 2003;17:488-95.

3. Heirholzer C, von Ruden C, Potzel T, Woltmann A, Buhren. Outcome analysis of retrograde nailing and less invasive stabilization system in distal femoral fractures. A retrospective analysis. Indian J Orthop. 2011;45:243-50
4. Markmiller M, Konrad G, Sudkamp N. Femur-LISS and distal femoral nail for fixation of distal femoral fractures: are there differences in outcome and complications? ClinOrthopRelat Res 2004Sep;426:252-7.

5. Morgan SJ, Hurley D, Agudelo JF. Retrograde femoral nail ing: an understanding of the intercondylar insertion site. $J$ Trauma 2006Jan;64:608151-4

6. Kawy SE, Ansara S, Moftah A, Shalabi H, Varughese V. Retrograde femoral nailingin elderly patients with supracondylar fracture femur; is it the answer fora clinical problem? Int Orthop2007Feb;31:83-6.

7. Zlowodki M, Williamson S, Cole PA, Zardiackas LD, Kregor PJ. Biomechanical evaluation of the less invasive stabilization system, angled blade plate, and retrograde intramedullary nail for the internal fixation of distal femur fractures. J Orthop Trauma 2004Sep;18:494-502.

8. Christodoulou A, Terzidis I, Ploumis A, Metsovitis S, Koukoulidis A, Toptsis C. Supracondylar femoral fractures in elderly patients treated with the dynamic condylar screw and the retrograde intramedullary nail: a comparative study of the two methods. Arch Orthop Trauma Surg.2005Mar;125:73-9

9. Nathan $\mathrm{H}$, Ian $\mathrm{H}$, Kaushik $\mathrm{H}$. Retrograde nailing versus fixedangle blade plating for supracondylar femoral fractures: A randomized controlled trial.ANZ J Surg 2006May;76:290-4.

10. Gonzalez Della Valle A, Leali A, Hass S. Etiology and surgical interventions for stiff total knee replacements. HSS J 2007Sep;3:182-9

11. Engh GA, Ammeen DJ. Perioprosthetic fractures adjacent to total knee implants: treatment and clinical results. InstrcourseLect 1998Jul;47:437-48.

12. Moehring HD. Flexible intramedullary fixation of femoral fractures. ClinOrthop 1988Dec;277:190-200.

13. Zickel RE, Hobeika P, Robbins DS. Zickelsupracondylar nails for fractures of the distal end of the femur. ClinOrthop 1986Nov;212:79-88.

14. Butler M, Brumback RJ, Ellison TS, Poka A, Bathon GH, Burgess AR. Interlocking intramedullary nailing for ipsilateral fractures of the femoral shaft and distal part of the femur. $J$ Bone Joint Surg Am 1991Dec;73:1492-502.

15. Leung KS, Shen WY, So WS, Mui LT, Grosse A. Interlocking intramedullary nailing for supracondylar and intercondylar fractures of the distal part of the femur. J Bone JointSurg Am 1991 Mar;73:332-40.

16. Seligson D, Kristian Tk. Use of the Wagner apparatus in complicated fractures of the distal femur. J Trauma 1978Dec;18:795-9.

17. Jeon $\mathrm{IH}$, Oh CW, Kim SJ, Park BC, Kyung HS, Ihn JC. Minimally invasive percutaneous plating of distal femoral fractures using the $d \mathrm{y} \mathrm{n}$ ami c c o n d y l a r s c rew. J Tr a uma 2004:57:1048-52.

18. AkibMajed Khan, Quen Oat Tang, Dominic Spicer. The Epidemiology of Adult Distal Femoral Shaft Fractures in a Central London Major Trauma Centre Over Five Years. Open Orthop J. 2017; 11:1277-1291.Kulkarni SG, Varshneya A, Kulkarni GS, Kulkarni MG, Kulkarni VS, Kulkarni RM. Antegradelnterlocking nailing for distal femoral fractures. J Ortho Surg. 2012;20(1):48-54.

19. Demirta AS, Azboy I, Gem M, Alemdar C. Comparison of retrograde intramedullary nailing and bridge plating in the treatment of extra-articular fractures of distal femur. ActaOrthopTraumatolTurc. 2014;48(5):521-6.

20. A Saw, CP Lau. Supracondylar nailing for difficult distal femur Fractures. J OrthopSurg2003Dec;11(2):141-7.

21. Heiney JP, Barnett MD, Vrabec GA, Schoenfeld AJ, Baji A, Njus GO. Distal femoral fixation: a biomechanical comparison of trigen retrograde intramedullary (i.m.) nail, dynamic condylar screw (DCS), and locking compression plate (LCP) condylar plate. J Trauma. 2009 Feb;66(2):443-9.

22. Demirtaş A, Azboy I, Özkul E, Gem M, Alemdar C. Comparison of retrograde intramedullary nailing and bridge 
plating in the treatment of extra-articular fractures of the distal femur. J ClinExp Med. 2016; 9(10).

23. Jihyeung Kim, Seung-Baik Kang, Kyungpyo Nam, Seung Hwan Rhee, Jong Won Won, Hyuk-Soo Han. Retrograde Intramedullary Nailing for Distal Femur Fracture with Osteoporosis. ClinOrthop Surg. 2012; 4(4):307-312.

24. David SM, Harrow ME, Peindl RD, Frick SL, Kellam JF. Comparative biomechanical analysis of supracondylar femur fracture fixation: locked intramedullary nail versus 95-degree angled plate. J Orthop Trauma. 1997; 11(5):344-50

25. Hierholzer Christian, Rüden Christian von, Pötzel Tobias, Woltmann Alexander, Bühren Volker. Outcome analysis of retrograde nailing and less invasive stabilization system in distal femoral fractures: A retrospective analysis. Indian $\mathrm{J}$ Orthop. 2011; 45(3):243-50
26. Lucas ES, Seligson D, Henry SL. Intramedullary supracondylar nailing of femoral fractures. ClinOrthop. 1993:296:200-6.

27. Leggon RE, Feldman DD. Retrograde femoral nailing: A focus of the knee. Am J Knee Surg. 2001;14:109-18

28. Marks DS, Isbister ES, Porter KM. Zickel supracondylar nailing for supracondylar femoral fractures in elderly or infirm patients. J Bone Joint Surg. 1994;76:596-601.

29. Tornetta P, Tiburzi D. Antegrade or retrograde femoral nailing. A prospective randomized trial. J Bone Joint Surg Br. 2000;82:652-4.

30. Handolin L, Pajarinen J, Lindahl J, Hirvensalo E. Retrograde intramedullary nailing in distal femoral fractures-results in a series of 46 consecutive operations. Injury. 2004; 35(5):51722. 